\title{
Osteopathic Medicine in Four Chronic Musculoskeletal Pain Diseases: An Observational Trial with Follow-Up
}

\author{
Gabriele Rotter $^{\mathrm{a}, \mathrm{b}}$ Sylvia Binting ${ }^{\mathrm{a}} \quad$ Tatjana Tissen-Diabaté $^{\mathrm{a}} \quad$ Miriam Ortiz $^{\mathrm{a}}$ \\ Benno Brinkhaus ${ }^{\text {a }}$ \\ anstitute of Social Medicine, Epidemiology and Health Economics, Charité - Universitätsmedizin Berlin, corporate \\ member of Freie Universität Berlin, Humboldt-Universität zu Berlin, and Berlin Institute of Health, Berlin, Germany; \\ ${ }^{b}$ Kurt-Singer-Institute for Music Physiology and Musicians Health, Hanns Eisler School of Music Berlin, Berlin, \\ Germany
}

\section{Keywords}

Chronic neck pain - Chronic low back pain · Chronic shoulder pain · Chronic knee pain - Osteopathic medicine

\begin{abstract}
Background and Aim: Patients with chronic musculoskeletal pain diseases (CMPDs) often use osteopathic medicine $(\mathrm{OM})$, although the changes in patients with pain diseases are still insufficiently investigated. This study aimed to observe changes along and after $\mathrm{OM}$ in addition to routine care on pain, functioning, and quality of life in patients with four CMPDs. Methods: In this observational trial with follow-up, patients suffering from chronic neck pain (CNP, $n=10$ ), chronic low back pain (CLBP, $n=10)$, chronic shoulder pain (CSP, $n=10)$, or chronic knee pain (CKP, $n=10$ ) received up to six OM sessions in addition to routine care. Results: $A$ total of 40 patients ( $73 \%$ female, mean age $47.7 \pm 8.3$ years, mean pain intensity $59.4 \pm 12.5 \mathrm{~mm}$, measured by a visual analog scale [VAS] 0-100 mm) were included. After 26 weeks, there was an improvement in the VAS pain score in the whole population (mean difference to baseline $-33.1 \mathrm{~mm}[95 \% \mathrm{Cl}-40.5$ to -25.7$])$, as well in the patients with the four diseases: CNP ( $-33.7 \mathrm{~mm}[-54.7$ to -12.6$]), \mathrm{CLBP}(-28.2 \mathrm{~mm}[-47.9$ to -8.4$])$, CSP (-32.4 [-46.8 to -18.0$])$, and CKP $(-38.1 \mathrm{~mm}[-49.1$ to -27.0]). Regarding disease-specific outcomes, we found improvements in CNP, as measured by the neck disability index (scale 0-50; mean difference -3.6 [-9.0 to 1.9]), CLBP, as measured by the low back pain rating scale (scale $0-60 ;-3.4$
\end{abstract}

[-12.5 to 5.7]), CSP, as measured by the disabilities of the arm, shoulder and hand score (scale $0-100 ;-13.4$ [-23.1 to -3.7]), and CKP, as measured by the Western Ontario and McMaster Universities Osteoarthritis Index (scale 0-96; -13.0 [-23.5 to -2.5$]$ ). These improvements persisted through week 52. No adverse events were observed. Conclusion: The study observed beneficial changes along and after the OM treatment in addition to routine care in patients with four different CMPDs. High-quality, multicenter randomized controlled trials are strongly needed to compare the effectiveness of OM and standard care interventions in treating CMPDs in the future. We have provided sufficient data for sample size calculations for these trials.

(C) 2021 The Author(s) Published by S. Karger AG, Basel

\section{Osteopathische Medizin in vier chronischen muskuloskeletalen Schmerzerkrankungen: Eine Beobachtungsstudie mit Follow-up}

\section{Schlüsselwörter}

Chronische zervikale Schmerzen - Chronische lumbale Schmerzen · Chronische Schulterschmerzen · Chronische Knieschmerzen · Osteopathische Medizin

Trial registration: German Clinical Trials Register DRKS00008319, Universal Trial Number (UTN): U1111-1169-9945.
Correspondence to:

Gabriele Rotter, gabriele.rotter@ charite.de 


\section{Zusammenfassung}

Hintergrund und Ziel: Patienten mit chronischen muskuloskeletalen Schmerzerkrankungen (CMPDs) nutzen oft osteopathische Medizin (OM), obwohl die Veränderungen bei Patienten mit Schmerzerkrankungen noch unzureichend untersucht sind. Ziel dieser Studie war es, Veränderungen während und nach der OM, in Ergänzung zur Routineversorgung, auf Schmerzen, Funktionsfähigkeit und Lebensqualität bei Patienten mit vier CMPDs zu beobachten. Methoden: In einer Beobachtungsstudie mit Follow-up erhielten Patienten, welche an chronischen zervikalen Schmerzen, (CNP, $n=$ 10), chronischen lumbalen Schmerzen (CLBP, $n=10$ ), chronischen Schulterschmerzen (CSP, $n=10)$, oder chronischen Knieschmerzen (CKP, $n=10$ ) litten, bis zu sechs OM Behandlungen zusätzlich zur Routinebehandlung. Ergebnisse: Insgesamt wurden 40 Patienten (73\% Frauen, mittleres Alter 47,7 $\pm 8,3$ Jahre) mit einer mittleren Schmerzintensität von 59,4 $\pm 12,5 \mathrm{~mm}$, gemessen auf einer Visuellen Analog Skala (VAS, 0-100 mm) eingeschlossen. Nach 26 Wochen bestand eine Verbesserung auf der VAS Schmerz in der Gesamtpopulation (mittlere Differenz zu Baseline -33,1 mm [95\% KI -40,5; -25,7]), als auch bei den Patienten in allen vier Erkrankungen: CNP $(-33,7 \mathrm{~mm}[-54,7 ;-12,6]), \operatorname{CLBP}(-28,2 \mathrm{~mm}[-47,9 ;-8,4])$, CSP $(-32,4[-46,8 ;-18,0])$, und CKP $(-38,1 \mathrm{~mm}[-49,1$; $-27,0])$. Hinsichtlich krankheitsspezifischer Zielparameter fanden wir Verbesserungen im CNP, gemessen mittels Neck Disability Index (Skala 0-50; mittlere Differenz $-3,6[-9,0 ; 1,9])$, CLBP, gemessen mittels Low Back Pain Rating Scale (Skala 0-60; -3,4 [-12,5; 5,7]), CSP, gemessen mittels Disabilities of the Arm, Shoulder and Hand Score (Skala 0-100; -13,4 [-23,1;-3,7]) und CKP, gemessen mittels Western Ontario and McMaster Universities Osteoarthritis Index (Skala 0-96; -13,0 [-23,5;-2,5]). Die Verbesserungen hielten bis zur Woche 52 an. Es wurden keine unerwünschten Ereignisse beobachtet.Schlussfolgerung: Die Studie beobachtete positive Veränderungen während und nach der OM-Behandlung, in Ergänzung zur Routineversorgung, bei Patienten mit vier verschiedenen CMPDs. Qualitativ hochwertige, multizentrische randomisierte kontrollierte Studien sind dringend erforderlich, um die Wirksamkeit von OM-Behandlungen und Standardbehandlungen bei der Behandlung von CMPDs in Zukunft zu vergleichen. Wir haben ausreichende Daten für die Berechnung der Stichprobengröße für diese Studien zur Verfügung gestellt.

(c) 2021 The Author(s).

Published by S. Karger AG, Basel

\section{Introduction}

Low back pain, neck pain, and chronic musculoskeletal pain diseases (CMPDs) in general lead to a large disease burden globally, and CMPDs constitute one of the leading causes of ill health $[1,2]$. The 12 -month prevalence of chronic knee pain (CKP) among patients aged 50 years and older treated by general practitioners was reported to be $25.3 \%$ [3]. In a German cross-sectional study ( $n=2,510$ participants), the 3 -month prevalence was $25 \%$ for chronic low back pain (CLBP), 18\% for chronic neck pain (CNP), 11\% for chronic shoulder pain (CSP) in the right shoulder, and 9\% for CSP in the left shoulder [4]. These CMPDs are recommended to be treated by a multimodal regime, including analgesics, educational interventions, exercise, and manual treatments [5-13]. However, long-term medication with analgesics might result in adverse events, and there is growing interest in nonpharmacological treatment options, including treatments originating from complementary and integrative medicine [14-17].

Osteopathic medicine $(\mathrm{OM})$ is a component of complementary and integrative medicine. In an Australian adult population, OM was reported to be used by $4.6 \%$ of the patients within the last 12 months $(n=1,067$ interviews) [18]. Patients seek OM mostly for pain symptoms not only in the lower back (36\%) and neck (15\%) but also in the shoulder (7\%) [19]. OM relies on manual contact for diagnosis and treatment and emphasizes the structural and functional integrity of the body, including skeletal, arthrodial, and myofascial structures and related vascular, lymphatic, and neural elements [20]. These structures include the musculoskeletal, visceral, and so-called craniosacral system. In Europe, OM is commonly administered by nonphysicians (in Germany, often physiotherapists and "Heilpraktiker" [healing practitioners]) or physicians as a diagnosis-related and individualized treatment (osteopathic manipulative treatment) and additionally offers self-training instructions for postural improvement. There is some evidence that OM might be effective in treating CMPDs. Previous studies have indicated that $\mathrm{OM}$ is effective in relieving pain in patients with CNP [21], relieving pain and improving function in patients with CLBP $[22,23]$, and relieving shoulder pain $[24,25]$. Further, unpublished randomized controlled trials (RCTs) suggest beneficial effects of OM for shoulder pain [26] and knee pain [27].

However, until now, to the best of the authors' knowledge, a prospective observation of six routine OM treatments in patients with various CMPDs; outcomes for pain, quality of life, disease-specific function; restrictions in activities of daily living (ADL); and the utilization of additional therapies over a long follow-up period has not been published.
Rotter/Binting/Tissen-Diabaté/Ortiz/ Brinkhaus 
The aims of this observational trial with follow-up were to assess data on pain, functioning, and quality of life in patients suffering from CNP, CLBP, CSP, or CKP, who received $\mathrm{OM}$ in addition to German physician routine care setting, and to investigate the study feasibility. A further aim was to provide sufficient data for sample size calculations for future RCTs.

\section{Methods}

\section{Study Design and Setting}

The observational trial with follow-up included 40 adult patients, with 10 patients in each of the four groups of CMPDs (CNP, CLBP, CSP, or CKP). The outcomes were assessed after 12, 26, and 52 weeks. The study was performed at the outpatient clinic for Integrative Medicine of the Charité - Universitätsmedizin in Berlin, Germany.

\section{Patients}

Patients were recruited by the website of the outpatient department for integrative medicine and the intranet of Charité - Universitätsmedizin Berlin. Patients between 30 and 65 years of age with a clinical diagnosis of CNP, CLBP, CSP, or CKP (disease duration with the specific pain of at least 12 weeks) and an average visual analog scale (VAS) score for pain intensity $(0-100 \mathrm{~mm}, 0=$ no pain, $100=$ worst imaginable pain) of at least $40 \mathrm{~mm}$ within the last 7 days with respect to the diagnosis were included. The main exclusion criteria were a history of OM treatment within the last 12 months; musculoskeletal pain due to known malignant diseases, infections, a previous accident, known or suspected primary or secondary bone tumor, known vascular anomaly, peripheral or central neurological symptoms, rheumatic diseases, or the presence of implants/endoprostheses in the respective body region; a body mass index higher than 30 ; the intake of centrally acting analgesics; and the presence of pregnancy or lactation.

\section{Exposure}

After inclusion, the patients received six individualized diagnosis-related OM treatment sessions that lasted $45 \mathrm{~min}$ each, with 3 - to 4 -week intervals (during 26 weeks), in addition to routine care. An on-demand dose of $500 \mathrm{mg}$ paracetamol up to four times daily was provided in the first 26 weeks. The patients were discouraged from taking analgesics other than paracetamol. No changes were made to the other conventional or complementary therapy regimens received by the patients. The diagnostics method, treatment strategy, and treatment interval were intentionally made to be the same as those usually used in our outpatient clinic for integrative medicine. At the beginning of each session, a short anamnesis and physical examination were performed to determine the $\mathrm{OM}$ treatment strategy for the respective session. For the treatment techniques performed for the musculoskeletal, visceral, and craniosacral systems, the patients were treated in a standing, sitting, or lying position with or without active participation. Posturologic and ergonomic advice was included. The OM treatment was administered by a medical doctor who specialized in orthopedic surgery (G.R.), completed a 5-year part-time OM training program $(1,350 \mathrm{~h})$, holds an MSc degree in osteopathy, and had longterm experience in OM treatment.

\section{Outcome Parameters}

All parameters were measured at baseline and after 12,26, and 52 weeks using standardized questionnaires, including validated patient-reported outcome measurements. Because this is an exploratory study, no primary outcome parameters were determined. All patients rated their average perceived pain in the respective body region within the last 7 days using a VAS [28]. For all CMPDs, the minimal clinically important difference (MCID) between baseline and 26 weeks (after 6 treatments) was considered to be $15 \mathrm{~mm}[29,30]$. The criteria for a substantial clinical benefit (SCB) was considered to be $26.5 \mathrm{~mm}$ [31]. Health-related quality of life was measured by the 12-item short form health survey (SF12), with an MCID of 5 points [32-35].

In addition, for each diagnosis group, a disease-specific outcome parameter, listed below, was measured. In patients with $\mathrm{CNP}$, neck function was assessed by the neck disability index (NDI, scores ranging from 0 to 50, MCID of 3.0 points, SCB of 8.4 points) $[31,36,37]$. In patients with CLBP, pain was evaluated with the pain subscale of the low back pain rating scale (scores ranging from 0 to 60 , MCID of 1.2 points) [38-40]. In patients with CSP, upper extremity function was assessed by the disabilities of the arm, shoulder and hand questionnaire (DASH, scores ranging from 0 to 100, MCID of 8 points in the total score) [41-43]. In addition, the DASH includes an optional questionnaire module for sports/music that does not influence the DASH total score. In patients with CKP, knee function was evaluated by two outcome measurements, the Western Ontario and McMaster Universities Osteoarthritis Index (WOMAC, total scores ranging from 0 to 96 , MCID of 10 points in the total score) [44-47] and the Lequesne index (total scores ranging from 0 to 24 , MCID of a $40 \%$ change in each score) [48-51].

Furthermore, the following parameters related to the respective CMPD with respect to the last 4 weeks were assessed: days with restrictions in activities of daily living (ADL), analgesic intake (reported as the number of patients taking analgesics), and the use of additional therapies. Furthermore, treatment expectations ("highly effective," "effective," "slightly effective," "not effective") and outcome expectations ("healing," "substantial improvement in symptoms," "modest improvement in symptoms," "no improvement") were rated by the study physician and by the patients. In addition, parameters related to the safety of OM, including therapy-related adverse events and serious adverse events, were evaluated.

\section{Statistical Analysis}

As this was an observational trial with follow-up, no sample size calculation was performed. A total of 10 patients per CMPD group was considered sufficient to achieve the objectives of the study. The collected data were evaluated descriptively: mean values, SDs, medians, and interquartile ranges, additionally in nonnormally distributed data, and frequencies and percentages for the entire group and by CMPD group. The pre- and posttreatment outcome parameters were exploratively compared by mean differences. All confidence intervals were two-sided. The results are presented descriptively. The evaluation was carried out according to the intention-to-treat principle with the full analyses set and without the substitution of missing values. The statistical analysis was performed using SAS software, version 9.4 [52], and R, version 3.6.3 [53].

\section{Results}

\section{Patients}

Among the 91 eligible patients, 40 were enrolled (as planned, with 10 patients in each of the 4 CMPD groups, CNP, CLBP, CSP, and CKP) between June 2015 (first pa- 


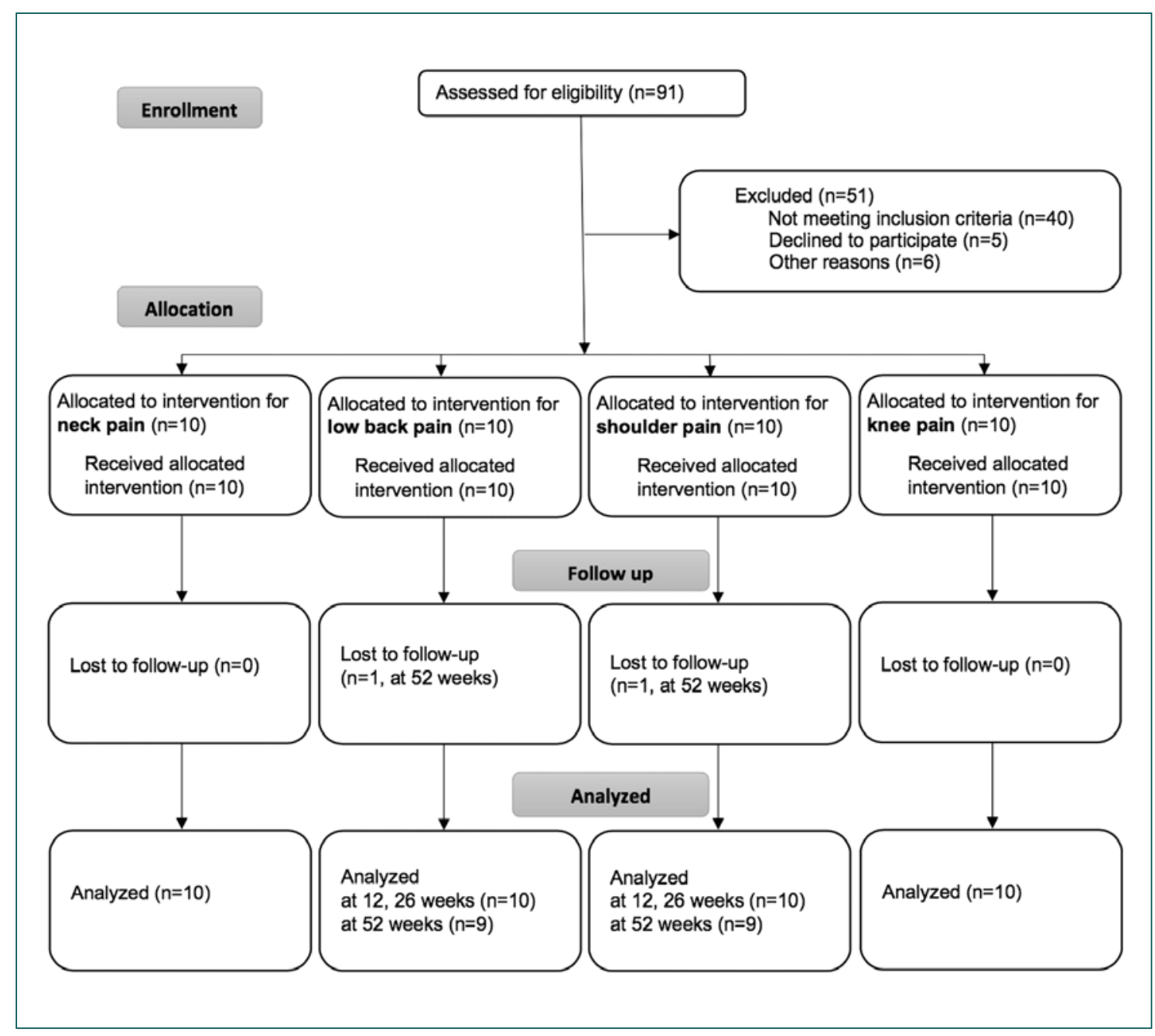

Fig. 1. Recruitment, treatment, and follow-up of patients with chronic neck pain, chronic low back pain, chronic shoulder pain, and chronic knee pain.

tient included) and January 2017 (last patient included) (Fig. 1). The group of patients with CLBP was complete first (January 2016), followed by the groups CNP (July 2016), CKP (October 2016), and finally CSP (January 2017). Two patients (one with CLBP and one with CSP) did not return the questionnaires after 52 weeks. There were no other patients lost to follow-up. To return the questionnaires one reminder had to be sent to 22 patients after 12 weeks, 19 patients after 26 weeks, and 21 patients after 52 weeks. During the entire study period, a total of 34 patients had to be reminded to return the questionnaires. Apart from that, the questionnaires were mostly well accepted and carefully completed.

At baseline, the mean age of all the patients $(n=40)$ was $47.7 \pm 8.3$ years (mean \pm SD) (Table 1 ), with a range from 30 to 62 years. Twenty-nine patients $(72.5 \%)$ were female, and the mean duration of the specific CMPD symptoms was $9.0 \pm 10.3$ years. At least one nondrug treatment for the respective CMPD within the last 6 weeks was reported by 26 patients (65\%). In the past, 24 patients $(60.0 \%)$ had received OM, 10 (25.0\%) of whom received OM specifically for the respective CMPD. Analgesics for the respective CMPD were taken within the last 6 weeks by 20 patients (50.0\%). The mean VAS score for pain was $59.4 \pm 12.5 \mathrm{~mm}$, the mean SF-12 physical component scale (SF-12 PCS) score was $39.2 \pm 8.0$, and the mean SF-12 mental component scale (SF-12 MCS) score was $48.6 \pm 9.2$. Regarding OM treatment expectations, the study physician mostly expected OM to be "effective" (55.0\%) and "slightly effective" (40.0\%), whereas the patients mostly expected it as "effective" (50.0\%) and "highly effective" (47.5\%). With respect to the outcome expectations, the study physician tended to report "substantial improvement in symptoms" (37.5\%) or "modest improvement in symptoms" (62.5\%), whereas the patients tended to report "substantial improvement in symptoms" (80.0\%). For the duration of symptoms, restrictions in $\mathrm{ADL}$, and pain intensity, as measured by the 
Table 1. Baseline characteristics of study participants

\begin{tabular}{|c|c|c|c|c|c|}
\hline & $\begin{array}{l}\text { Total } \\
(n=40)\end{array}$ & $\begin{array}{l}\text { Neck pain } \\
(n=10)\end{array}$ & $\begin{array}{l}\text { Low back pain } \\
(n=10)\end{array}$ & $\begin{array}{l}\text { Shoulder pain } \\
(n=10)\end{array}$ & $\begin{array}{l}\text { Knee pain } \\
(n=10)\end{array}$ \\
\hline Sex, female & $29(72.5)$ & $7(70.0)$ & $7(70.0)$ & $7(70.0)$ & $8(80.0)$ \\
\hline Age, years & $47.7 \pm 8.3$ & $49.2 \pm 4.8$ & $45.3 \pm 8.1$ & $47.2 \pm 9.7$ & $49.1 \pm 10.3$ \\
\hline Profession, employed & $30(75.0)$ & $8(80.0)$ & $8(80.0)$ & $7(70.0)$ & $7(70.0)$ \\
\hline \multirow[t]{2}{*}{ Duration of the specific CMPD symptoms, years } & $9.0 \pm 10.3$ & $11.4 \pm 11.7$ & $6.8 \pm 6.1$ & $5.7 \pm 4.5$ & $12.2 \pm 15.1$ \\
\hline & $5.3[8.0]$ & $8.5[5.0]$ & $4.5[7.8]$ & $5.3[7.1]$ & $6.5[11.3]$ \\
\hline \multirow[t]{2}{*}{ Restrictions in ADL, days } & $14.6 \pm 11.1$ & $14.5 \pm 11.8$ & $20.6 \pm 10.3$ & $14.2 \pm 10.6$ & $9.2 \pm 10.2$ \\
\hline & $15.0[20.5]$ & $9.0[21.2]$ & $22.5[13.2]$ & $12.5[17.2]$ & $4.5[18.8]$ \\
\hline Use of physical therapy last 4 weeks & $13(32.5)$ & $4(40.0)$ & $3(30.0)$ & $6(60.0)$ & 0 \\
\hline Physical therapy in the past for the respective CMPD & $33(84.6)$ & $9(90.0)$ & $7(77.8)$ & $10(100)$ & $7(70.0)$ \\
\hline Osteopathy in the past & $24(60.0)$ & $8(80.0)$ & $4(40.0)$ & $6(60.0)$ & $6(60.0)$ \\
\hline For the respective CMPD & $10(25.0)$ & $4(40.0)$ & $3(30.0)$ & 0 & $3(30.0)$ \\
\hline For other disease & $17(42.5)$ & $5(50.0)$ & $2(20.0)$ & $6(60.0)$ & $4(40.0)$ \\
\hline CMPD-related analgesics intake (last 4 weeks) & $20(50.0)$ & $5(50.0)$ & $4(40.0)$ & $8(80.0)$ & $3(30.0)$ \\
\hline Medications for other diagnoses & $30(75.0)$ & $6(60.0)$ & $6(60.0)$ & $9(90.0)$ & $9(90.0)$ \\
\hline \multirow{2}{*}{ Visual analogue scale pain $(0-100 \mathrm{~mm})^{*}$} & $59.4 \pm 12.5$ & $62.3 \pm 10.8$ & $62.0 \pm 14.8$ & $57.3 \pm 14.8$ & $56.0 \pm 9.4$ \\
\hline & $57.2[11.0]$ & $60.0[18.8]$ & $57.5[10.8]$ & $55.2[13.8]$ & $57.0[9.8]$ \\
\hline \multicolumn{6}{|l|}{ SF-12 } \\
\hline Physical Component Scale $(0-100)^{* *}$ & $39.2 \pm 8.0$ & $36.9 \pm 8.5$ & $39.6 \pm 8.1$ & $38.8 \pm 6.4$ & $41.8 \pm 9.1$ \\
\hline \multirow[t]{2}{*}{ Mental Component Scale $(0-100)^{* *}$} & $48.6 \pm 9.2$ & $42.9 \pm 10.3$ & $51.7 \pm 9.0$ & $47.2 \pm 7.4$ & $52.5 \pm 7.7$ \\
\hline & $50.8[14.7]$ & 40.0 [17.9] & $54.7[7.4]$ & $47.8[10.6]$ & $55.0[8.2]$ \\
\hline NDI $(0-50)^{*}$ & - & $15.1 \pm 5.9$ & - & - & - \\
\hline Low Back Pain Rating Scale $(0-60)^{*}(n=9)$ & & - & $19.3 \pm 4.7$ & - & - \\
\hline $\mathrm{DASH}(0-100)^{*}$ & - & - & - & $55.7 \pm 13.4$ & - \\
\hline WOMAC total score $(0-96)^{*}$ & - & - & - & - & $22.4 \pm 13.7$ \\
\hline Lequesne index of severity $(0-24)^{*}$ & - & - & - & - & $5.3 \pm 3.7$ \\
\hline
\end{tabular}

Data are presented as mean $\pm \mathrm{SD}$, median $[\mathrm{IQR}]$, or $n(\%) .{ }^{*}$ Lower values indicate better status. ${ }^{* *}$ Higher values indicate better status; in cases of non-normal distribution median and IQR are additionally reported. ADL, activities of daily living; CMPD, chronic musculoskeletal pain disease; DASH, Disabilities of Arm, Shoulder and Hand; NDI, Neck Disability Index Score; IQR, interquartile range; SF-12, 12-item Short Form Health Survey; WOMAC, Western Ontario and McMaster Universities Osteoarthritis Index.

VAS, we found distinct differences between the mean and median values.

\section{Exposure}

The interventions were performed as described in the Methods. Regarding adherence to the OM interventions, $n=39$ patients underwent all 6 treatments. One patient with CNP underwent only one intervention because of personal reasons but did not drop out of the study and returned all questionnaires throughout the 52 weeks of follow-up.

\section{Outcomes}

\section{VAS Pain}

In the whole study population, pain intensity, as measured by the VAS, improved after 12 weeks and approximately three OM sessions (mean difference to baseline $-29.3 \mathrm{~mm}[-35.7$ to -23.0$]$ ) with a clinically stable improvement after 26 weeks and 6 treatments (mean difference to baseline $-33.1 \mathrm{~mm}[-40.5$ to -25.7$])$. The im- provements had a substantial clinical benefit (SCB criteria change of $26.5 \mathrm{~mm}$ reached, Table 2). The largest improvement after 26 weeks was observed in CKP (mean difference to baseline $-38.1 \mathrm{~mm}[-49.1$ to -27.0$]$ ), and the lowest was observed in CLBP $(-28.2 \mathrm{~mm}[-47.9$ to -8.4$])$. Improvements persisted through the follow-up conducted at week 52 (mean difference to baseline $-34.9[-42.4$ to -27.5]) (Fig. 2).

\section{Health-Related Quality of Life with SF-12}

After 12 weeks, there was a tendency to an overall improvement in the SF-12 PCS score, with a mean difference to baseline of 4.9 (1.9-7.9), but not in the SF-12 MCS score (0.08 [ -2.2 to 3.8$])$. Similarly, after 26 weeks, the SF-12 PCS score mean difference to baseline (6.9 [4.29.5]) but not the SF-12 MCS score (-0.02 [ -3.1 to 3.0]) improved (Table 2). The improvement in SF-12 PCS score after 26 weeks was clinically important (MCID 5 points) and persisted through week 52 (mean difference to baseline 6.7 [3.7-9.7]) (Fig. 3). 


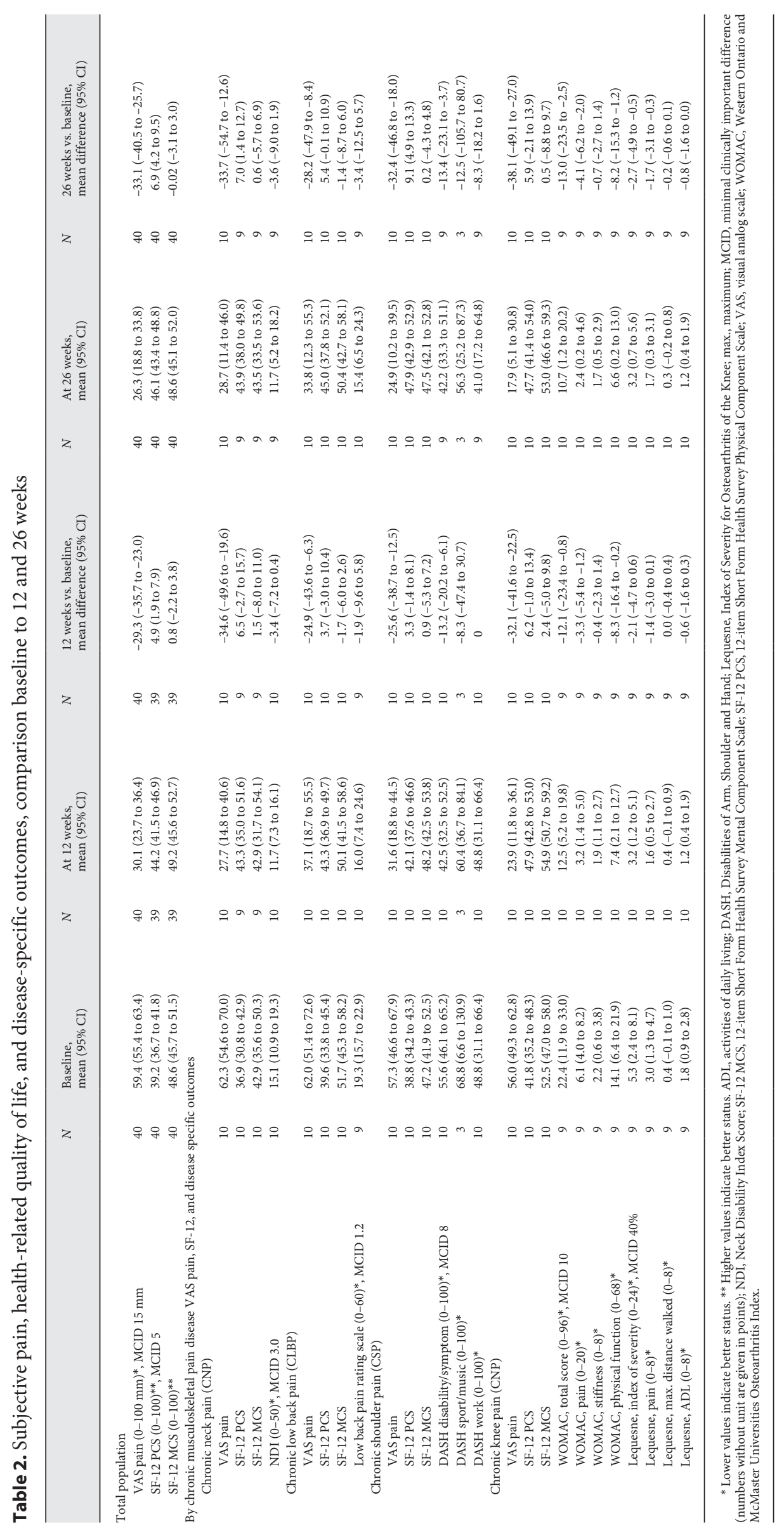




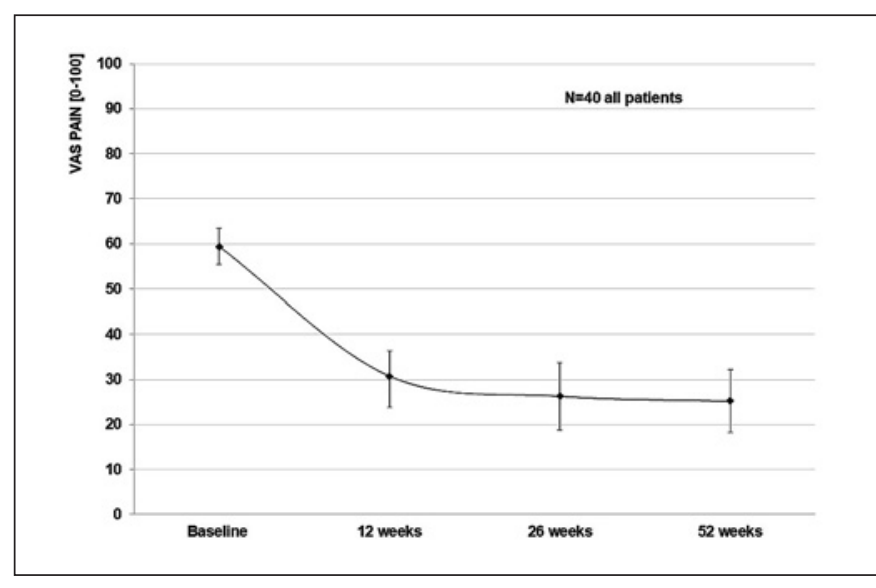

Fig. 2. Visual analog scale (VAS) pain through 52 weeks in all four chronic musculoskeletal pain diseases. Values are means and $95 \%$ CIs.

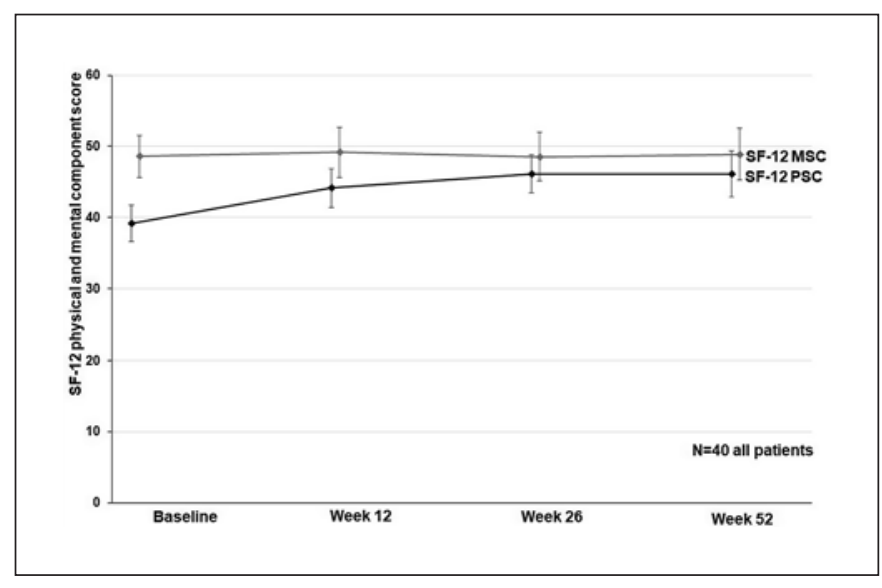

Fig. 3. Estimated mean scores of the 12 -item Short Form Health Survey (SF-12) Physical Component Scale (PCS) and Mental Component Scale (MCS) over 52 weeks. Values are means and 95\% CIs.

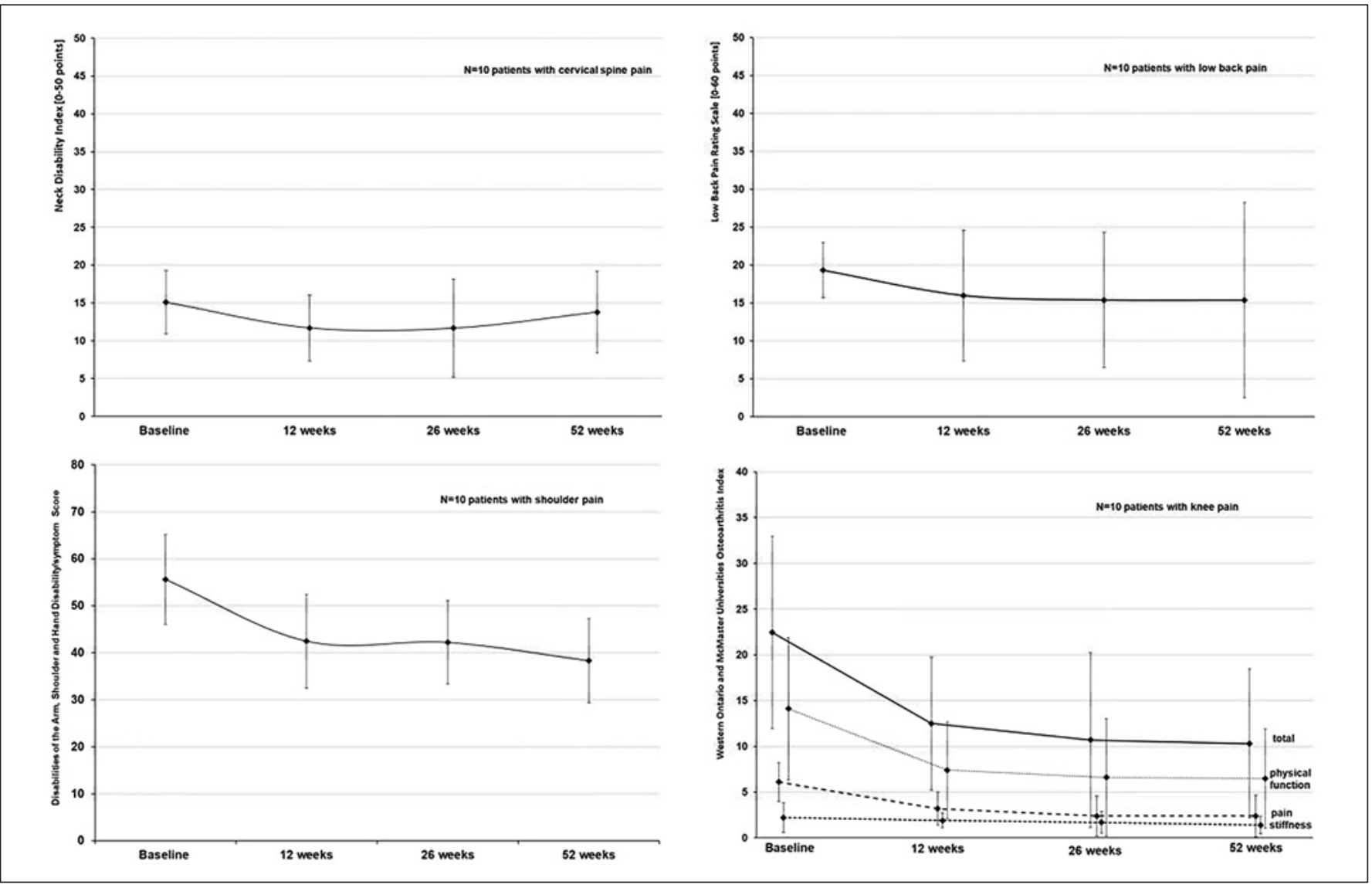

Fig. 4. Estimated mean scores for Neck Disability Index, Low Back Pain Rating Scale, Disabilities of Arm, Shoulder and Hand Score, and Western Ontario and McMaster Universities Osteoarthritis Index through 52 weeks in the according diagnosis group. Values are means and 95\% CIs.

Disease-Specific Outcomes

All disease-specific outcomes showed at least a tendency toward improvement over time in the respective study populations of 10 patients (Table 2; Fig. 4).
Among the CNP patients, we found clinically relevant (MCID 3.0 points) improvements in the NDI score from baseline to 12 weeks (mean difference [ $95 \%$ CI] $-3.4[-7.2$ to 0.4$])$ and versus 26 weeks $(-3.6[-9.0$ 
to 1.9]). For patients with CLBP, a clinically relevant (MCID 1.2 points) improvement in the low back pain rating scale was observed after 12 weeks $(-1.9$ [ -9.6 to $5.8])$ and after 26 weeks ( -3.4 [ -12.5 to 5.7$])$. In the ten patients with CSP, a clinically relevant (MCID 8 points) functional improvement in the DASH disability/symptom score was found from baseline to 12 weeks $(-13.2[-20.2$ to -6.1$])$ and to 26 weeks $(-13.4$ [ -23.1 to -3.7$])$. Only $n=3$ patients filled out the questionnaires for the optional sport/music score. In the patients with CKP, a clinically relevant improvement in function (MCID 10 points) according to the WOMAC total score was observed after 12 weeks $(-12.1$ [ -23.4 to -0.8$]$ ), and additional improvement was observed after 26 weeks $(-13.0$ [ -23.5 to -2.5$])$. After 26 weeks, we observed a tendency for improvements in the WOMAC subscale scores for pain $(-4.1[-6.2$ to $-2.0]$ ), stiffness ( -0.7 [ -2.7 to 1.4$]$ ), and physical function $(-8.2[-15.3$ to -1.2$])$. Some improvements were also observed in the Lequesne index of severity after 12 weeks $(-2.1$ [ -4.7 to 0.6$])$ and 26 weeks $(-2.7$ [ -4.9 to -0.5$]$ ). The observed improvement, $39.6 \%$, did not reach the MCID (40\%).

After 52 weeks, the improvements in the diseasespecific parameters persisted in the CLBP (low back pain rating scale score mean [95\% CI] 15.4 [2.5-28.2]), CSP (DASH disability/symptom score 38.3 [29.4$47.2]$ ), and CKP groups (WOMAC total score 10.3 [2.1-18.5]) but not in the CNP group (NDI 13.8 [8.419.2]) (Fig. 4).

Restrictions in Activities of Daily Living, Analgesics Intake, and the Use of Additional Therapies for CMPDs over the Last 4 Weeks

The number of days with restrictions in ADL over the last 4 weeks decreased from baseline to 12 weeks (overall mean of 14.6 vs. 7.8 days) and decreased further to 26 weeks for the whole study population and within every CMPD group. Only the CNP and CSP groups did not show additional improvement after 52 weeks (Table 3 ). The number of patients taking analgesics decreased in the whole study population from baseline to 26 weeks (Table 4). In the patients with CNP and CLBP, the number of patients taking analgesics remained unchanged from baseline to 26 weeks. The reduction in analgesic intake remained fairly low (overall by 18.4 percentage points) through 52 weeks. With regard to the respective $\mathrm{CMPD}$, in the whole population, the number of patients undergoing physical therapy decreased from $n=13$ (32.5\%) at baseline to $n=7(17.5 \%)$ at 12 weeks but increased again to $n=12(30.0 \%)$ at 26 weeks (Table 4$)$. The number of patients who used additional complementary medicine decreased from baseline to 26 weeks from $n=12(30.0 \%)$ to $n=8(20.0 \%)$. Additionally, the 
Table 4. Number of patients using additional medical aid for the respective musculoskeletal pain disease

\begin{tabular}{|c|c|c|c|c|}
\hline & $\begin{array}{l}\text { Baseline } \\
(n=40)^{*}\end{array}$ & $\begin{array}{l}\text { At } 12 \text { weeks } \\
(n=40)^{*}\end{array}$ & $\begin{array}{l}\text { At } 26 \text { weeks } \\
(n=40)^{*}\end{array}$ & $\begin{array}{l}\text { At } 52 \text { weeks } \\
(n=38)^{*}\end{array}$ \\
\hline Patients taking analgesics $(n=40$, last week)** & $20(50.0)$ & $13(32.5)$ & $10(25.0)$ & $12(31.6)$ \\
\hline Ibuprofen & $15(37.5)$ & $9(22.5)$ & $6(15.0)$ & $7(18.4)$ \\
\hline Diclofenac & $4(10.0)$ & $3(7.5)$ & $4(10.0)$ & $2(5.2)$ \\
\hline Metamizol & $4(10.0)$ & $4(10.0)$ & $2(5.0)$ & $2(5.2)$ \\
\hline Paracetamol & 0 & $1(2.5)$ & 0 & $1(2.6)$ \\
\hline Flupirtin & $1(2.5)$ & 0 & 0 & 0 \\
\hline Indometacin & 0 & 0 & 0 & $1(2.6)$ \\
\hline \multicolumn{5}{|l|}{ Patients taking analgesics per diagnosis group } \\
\hline Neck pain $(n=10)$ & $5(50.0)$ & $5(50.0)$ & $5(50.0)$ & $5(50.0)$ \\
\hline Low back pain ( $n=10, n=9$ after 52 weeks) & $4(40.0)$ & $3(30.0)$ & $4(40.0)$ & $1(11.1)$ \\
\hline Shoulder pain ( $n=10, n=9$ after 52 weeks) & $8(80.0)$ & $5(50.0)$ & $1(10.0)$ & $3(30.3)$ \\
\hline Knee pain $(n=10)$ & $3(30.0)$ & 0 & $1(10.0)$ & $3(30.0)$ \\
\hline \multicolumn{5}{|l|}{ Patients using non-drug therapy (last 4 weeks)** } \\
\hline Use of physical therapy** & $13(32.5)$ & $7(17.5)$ & $12(30.0)$ & $10(26.3)$ \\
\hline Physiotherapy & $10(25.0)$ & $4(10.0)$ & $5(12.5)$ & $4(10.5)$ \\
\hline Exercise & 0 & 0 & 0 & $2(5.3)$ \\
\hline Massage & $3(7.5)$ & $4(10.0)$ & $4(10.0)$ & $2(5.3)$ \\
\hline Thermotherapy & $6(15.0)$ & $4(10.0)$ & $5(12.5)$ & $4(10.5)$ \\
\hline Other & $6(15.0)$ & $1(2.5)$ & $5(12.5)$ & $5(13.2)$ \\
\hline Use of complementary medicine** & $12(30.0)$ & $10(25.0)$ & $8(20.0)$ & $10(26.3)$ \\
\hline Homeopathy & $1(2.5)$ & $1(2.5)$ & $1(2.5)$ & 0 \\
\hline Autogenic training & 0 & 0 & 0 & $2(5.3)$ \\
\hline Yoga & $7(17.5)$ & $3(7.5)$ & $1(2.5)$ & $5(13.2)$ \\
\hline Ayurveda & 0 & $1(2.5)$ & 0 & 0 \\
\hline Herbal therapy & $1(2.5)$ & $1(2.5)$ & 0 & $1(2.6)$ \\
\hline Biofeedback & 0 & 0 & 0 & 0 \\
\hline Bioresonance & 0 & 0 & 0 & 0 \\
\hline Feldenkrais & 0 & 0 & 0 & $1(2.6)$ \\
\hline Hypnotherapy & 0 & 0 & 0 & 0 \\
\hline Meditation & $4(10.0)$ & 0 & $1(2.5)$ & $2(5.3)$ \\
\hline Cupping & $1(2.5)$ & 0 & $1(2.5)$ & 0 \\
\hline Sessions with a healer & $1(2.5)$ & 0 & 0 & 0 \\
\hline Tai Qi & $1(2.5)$ & 0 & 0 & 0 \\
\hline Other & $6(15.0)$ & $4(10.0)$ & $5(12.5)$ & $5(13.2)$ \\
\hline Visiting a physician** & $24(60.0)$ & $9(22.5)$ & $9(22.5)$ & $9(23.7)$ \\
\hline General practitioner & $10(25.0)$ & $4(10.0)$ & $3(7.5)$ & $4(10.5)$ \\
\hline Rheumatologist & 0 & 0 & 0 & $1(2.6)$ \\
\hline Orthopedic surgeon & $12(30.0)$ & $5(12.5)$ & $6(15.0)$ & $7(18.4)$ \\
\hline Neurologist & $3(7.5)$ & $1(2.5)$ & $1(2.5)$ & 0 \\
\hline Surgeon & $2(5.0)$ & 0 & 0 & 0 \\
\hline Other physician & $6(15.0)$ & $2(5.0)$ & $3(7.5)$ & $2(5.3)$ \\
\hline Visiting a complementary medicine provider** & $4(10.0)$ & $4(10.0)$ & $4(10.0)$ & $6(15.8)$ \\
\hline Physician for homeopathy & $1(2.5)$ & $1(2.5)$ & $1(2.5)$ & 0 \\
\hline Physician for anthroposophical medicine & 0 & 0 & 0 & 0 \\
\hline Chinese medicine physician & $1(2.5)$ & $2(5.0)$ & 0 & $2(5.3)$ \\
\hline Physician for naturopathy & 0 & 0 & $1(2.5)$ & 0 \\
\hline Osteopath & $1(2.5)$ & 0 & $1(2.5)$ & $3(7.9)$ \\
\hline Healing practitioner & $2(5.0)$ & 0 & 0 & $1(2.6)$ \\
\hline
\end{tabular}

Data are presented as $n(\%) .{ }^{*}$ Percent are reported as valid percent. ${ }^{* *}$ More than one answer possible.

number of patients visiting another physician decreased from $n=24(60.0 \%)$ at baseline to $n=9$ at 12,26 , and 52 weeks. The number of patients visiting a complementary medicine provider remained at $n=4(10.0 \%)$ from baseline to 26 weeks and increased to $n=6$ at 52 weeks.

Safety

No adverse events were observed.

\section{Discussion}

In this observational trial with follow-up, we observed beneficial changes along and after the OM treatment in addition to Germans' physician routine care in patients with CMPDs. Furthermore, in a homogeneous research environment, the course of 4 CMPDs during and after OM treatments could be followed across diagnoses. Six OM sessions were associated with a substantial clinical 
improvement in pain intensity in patients with CMPD. Moreover, we observed clinically relevant disease-specific improvements in all CMPD groups except for the CKP group. Furthermore, we observed fewer restrictions in ADL, lower rate of use of analgesics and of additional therapies, and a clinically relevant improvement in the SF-12 PCS score but not in the SF-12 MCS score. Improvements with substantial clinical benefits were observed after only 3 OM treatments over 12 weeks, but additional benefits were observed after 26 weeks and 6 OM treatments. At 52 weeks, the improvements remained, including those in overall pain, the SF-12 PCS score, restrictions in $\mathrm{ADL}$, and disease-specific parameters for CLBP, CSP, and CKP, but not CNP. No adverse events were reported after OM treatment. Apart from the reminders to return the questionnaires, the study was straightforward to conduct, and patients with CLBP and CNP appeared to be the easiest to recruit into the study. Furthermore, patients showed high study adherence.

The study observed beneficial changes after OM in addition to routine care in patients with CMPDs. These results are supported by those of an observational study [54] from the United States of America (USA) focusing on the outcomes per OM office visit. In the prospective part of the study (299 office visits), patients' perceptions of the symptoms after the treatment were assessed. Immediately after $92 \%$ of the office visits for OM, patients reported feeling better or much better, and after $<2 \%$ of the office visits, they reported feeling worse; after 7 days (last follow-up), $72 \%$ of the patients reported feeling better or much better, and $6 \%$ reported feeling worse. The authors observed a short-term symptom relief after OM. Our study results included several validated patient-reported measurements and observed pain and functional improvements in patients with CMPDs. Furthermore, after 52 weeks, we found indications for lasting improvements. For future research, long-term follow-ups should be considered. Further, the inclusion of patients with different CMPD provides the opportunity to compare the symptom development of patients with different diagnoses under OM treatment. We must be aware that the mode of application of OM might differ across settings in Germany and the USA in accordance with the different training systems. For future comparisons of study results between the two countries, uniform OM definitions and standards are indispensable.

Though we observed improvements in CMPDs, there is some conflicting evidence regarding OM for CMPDs. A systematic review [55] investigated OM for various types of musculoskeletal pain and found no convincing evidence that it is effective. A more recent meta-analysis [56] that included 19 RCTs found some evidence suggesting that OM may be effective in treating patients suffering from neck pain and low back pain. Regarding CNP, a me- ta-analysis [21] that included 3 RCTs ( $n=123$ patients) found moderate-quality evidence for significant and clinically relevant effectiveness of OM in relieving pain, as measured by a 100-point scale (mean difference -13.04 [95\% CI -20.64 to -5.44$]$ ). A more recent RCT [57] reported that $\mathrm{OM}$ might be effective in reducing pain intensity in adult violinists and violists with CNP. For CLBP, a meta-analysis [21] that investigated the effectiveness of OM found moderate-quality evidence for a significant intergroup difference in favor of OM regarding pain, as measured by a 100 -point scale $(-14.93$ [ $95 \%$ CI -25.18 to $-4.68]$ ) based on 7 studies ( $n=769$ patients), and functional status, as measured using the standard mean difference in a random-effects model (mean difference, -0.32 [95\% CI -0.58 to -0.07$]$ ) based on 7 studies ( $n=771$ patients). The results of a recent meta-analysis [23] strengthen the evidence, and OM was more effective than control interventions in pain reduction (effect size -0.59 [95\% CI -0.81 to -0.36$], p<0.001)$ and in improving functional status (effect size $-0.42[-0.68$ to -0.15$], p=0.002$ ). Further, two RCTs investigated OM in patients with CLBP. One RCT [58] $(n=66)$ compared 5 OM and 5 sham OM interventions and found a clinically relevant improvement in pain and function between groups, in favor of OM. Another RCT [59] $(n=39)$ investigated two different $\mathrm{OM}$ approaches in 10 sessions in addition to exercise and found improvements in pain, function, and general health in both groups.

To further interpret our results, we used the MCID and SCB with respect to baseline. For pain, after 26 weeks, we observed an SCB in the whole population and in each of the four CMPD groups for pain. For the NDI, we considered the MCID to be 3.0 points, as described previously [31]. Using this value, we observed an MCID after 12 and 26 weeks, but we have to consider that slightly older publications report a larger range of MCID for the NDI, varying between 3.5 and 9.5 points (scores ranging from 0 to 50) $[60,61]$. On the basis of these references, we would not have observed an MCID in CNP. The same is true for the MCID of the low back pain rating scale, which we considered to have an MCID of 1.2 points [40], although another paper reported the overall MCID to be 6 points [62]. Furthermore, we considered the MCID for the DASH total score (range $0-100$ ) to be 8 points [43]. This MCID was calculated [43] using data from a prospective cohort study conducted by a multicenter collaborative study group, the Surgery of the Ulnar Nerve group, including 38 patients (mean age 49.3 years, range 23-70 years), in the USA. However, a more recent publication reported the MCID to be 25.41 points on the same scale in a convenience sample of 200 younger patients (mean age $39.4 \pm 12.6$ ) recruited from 3 outpatient physiotherapy clinics located in Iran [63]. However, the patient characteristics, especially the age of the population,
62

Complement Med Res 2022;29:53-66 DOI: $10.1159 / 000518311$
Rotter/Binting/Tissen-Diabaté/Ortiz/ Brinkhaus 
in the first mentioned study [43] more closely resemble those of our study population.

In our study, no adverse events were reported in the 40 patients. However, the study population was too small to draw conclusions for treatment safety. In the United Kingdom, in private OM practices, a total of 1,630 complete datasets were collected [19]. Osteopaths performed OM treatments in addition to other treatments, including counselling, acupuncture and electrotherapy. In $n=969$ (54\%) patients, no adverse events after first treatment were experienced; in $n=1,260$ (77\%), no adverse events were observed after subsequent treatments. The authors stated that the treatment provided was safe and did not yield severe or moderately severe adverse events. A recent OM study in the USA [64] that recorded adverse events at 1,847 office visits in 884 patients ( $75 \%$ female, mean age $51.8 \pm 15.8$ years) found the incidence rate for adverse events to be $2.5 \%$ (95\% CI $1.3-4.7 \%$ ). The most common adverse event was pain/discomfort, with an incidence of $0.9 \%(0.5-1.6 \%)$. Within our study population $(n=40)$, this incidence suggests that one patient may have experienced an adverse event. An explanation for no adverse events being reported in this study might be that although the study physician asked patients about adverse events at each treatment session (as performed in routine care) and patients were encouraged to contact the study center if they experience adverse events, we did not provide a diary for the documentation of adverse events. For future research, patients should be provided with diaries to document adverse events in a timely manner. Adverse events, especially severe adverse events, might seldom occur in patients treated with OM. Therefore, to further investigate adverse events related to OM, we advise designing larger and multicenter studies.

The main strength of this trial is that we conducted the study in a university research environment. To the best of our knowledge, this is the first European OM study in patients with CMPDs conducted in a university research environment following the quality standards of the Declaration of Helsinki [65] and the ICH-GCP guidelines, including prospective trial registration and ethics approval. Another strength is the long follow-up of 52 weeks during which long-term changes in patients with CMPDs were observed. OM treatment was performed by a well-trained provider, an osteopath who was also an orthopedic physician, with the individualized diagnosis-related osteopathic treatment method that is typically used.

However, the study has various limitations. First, the study observed only a small number of patients in total and per diagnosis group. Furthermore, this study was a single-center study recruiting at one university and involving only one provider with good but very specific training, clearly limiting the generalizability of our results. In addition, it applied only subjective outcome pa- rameters. However, we used a variety of standardized and validated patient-reported outcome measures. Another limitation is the study design. The absence of a control group follows the empirical approach of health care providers in routine care but limits the interpretation of the observed changes. The reported improvements may have been caused by known study effects, including observer effects $[66,67]$ and regression to the mean. Such study effects impact the results less in studies including a control group, and interventional trials like RCTs. However, this study was designed to observe changes along and after the OM treatment in addition to routine care. Furthermore, prior to the study, we empirically observed that patients seeking $\mathrm{OM}$ in addition to routine care often have a strong desire to undergo the desired treatment within a reasonable timeframe. By omitting an observed control group, we could immediately include all interested patients and provide them with OM treatment. Overall, the observed changes have to be interpreted with caution, and the results reported here have to be validated in RCTs.

The effectiveness of OM in the treatment of CMPDs should be further investigated in studies such as larger high-quality RCTs because it might be an effective and safe nonpharmacological treatment option. This is especially important because adverse events in analgesics include gastrointestinal bleeding, drug-induced headache [14, 15], and other severe adverse events caused by opioids [16].

The results presented here provide data for sample size calculations for future OM RCTs. Future studies should investigate the effectiveness and efficacy of OM in RCTs by investigating specific therapeutic effects of $\mathrm{OM}$ in comparison with a sham procedure and other effective therapeutic methods. Sham procedures should simulate OM diagnostics and therapies [68], or include single sham techniques that are compared with verum techniques [69]. However, a systematic review [70] comparing sham procedures with OM showed that 43 studies used very heterogeneously different types of manual sham procedures and provided little information about their application. The authors emphasized the need for guidelines to design sham procedures [70]. In our opinion, sham OM should simulate OM diagnostic and therapeutic procedures in studies investigating the specific therapeutic effects of OM. Regarding the comparison of OM with other effective therapy methods, these therapies could include single therapies, such as physiotherapy and analgesic intake, or could include multimodal therapeutic approaches. The blinding of study participants, outcome assessors, and statisticians should be considered in future trials, although blinding might not be necessary, as recently discussed [71]. Future trials conducted on OM should include multiple centers to investigate the external validity and transferability of our results. Adverse events should be reported by patients in diaries. 


\section{Conclusion}

We observed beneficial changes along and after the $\mathrm{OM}$ treatment in addition to routine care in patients with four CMPDs. Moreover, the observational study was straightforward to conduct. Given the high rate of use of OM in CMPD patients, high-quality multicenter clinical RCTs are urgently needed. The data provided in this study are sufficient for sample size calculations.

\section{Acknowledgment}

We thank all patients who participated in this study. Furthermore, we thank the study nurse, Margit Cree, for screening patients, scheduling appointments, and collecting data and our team at the outpatient clinic. We thank the native English-speaking editors at American Journal Experts for editing our manuscript for English language, grammar, punctuation, spelling, and overall style (certificate verification key: D49E-8C68-25CE-2A1F-443E).

\section{Statement of Ethics}

The study was approved by the Ethics Committee, Charité Universitätsmedizin Berlin (approval number EA1/068/15, no addendums, the study was performed without any changes during the trial). All patients gave oral and written informed consent before inclusion in the study. This study (German Clinical Trials Register DRKS00008319, Universal Trial Number, UTN: U1111-
1169-9945) followed the standards of the Declaration of Helsinki [65] and the ICH-GCP guidelines. The study was an investigatorinitiated trial with no external funding sources.

\section{Conflict of Interest Statement}

Gabriele Rotter receives irregular lecture fees for teaching osteopathic medicine and musicians' medicine. She is a board member of the European Register for Osteopathic Physicians (EROP). The other authors do not have any conflicts of interest regarding this study.

\section{Funding Sources}

This research received no external funding.

\section{Author Contributions}

G.R. conceived, coordinated, and carried out the study, interpreted the data, and drafted the manuscript. S.B. managed the data, carried out the statistical analyses, interpreted the data, and revised the manuscript. T.T.-D. revised and carried out the statistical analyses and revised the manuscript. M.O. helped design the study and revised the manuscript. B.B. helped design the study and methodology, contributed to the interpretation of the data, and revised the manuscript. All authors have read and approved the final version of the manuscript and agree with the order in which the authors are listed.

\section{References}

1 James SL, Abate D, Abate KH, Abay SM, Abbafati C, Abbasi N, et al.; GBD 2017 Disease and Injury Incidence and Prevalence Collaborators. Global, regional, and national incidence, prevalence, and years lived with disability for 354 diseases and injuries for 195 countries and territories, 1990-2017: a systematic analysis for the Global Burden of DiseaseStudy2017.Lancet.2018 Nov;392(10159): 1789-858.

2 Steel N, Ford JA, Newton JN, Davis AC, Vos $T$, Naghavi $M$, et al. Changes in health in the countries of the UK and 150 English Local Authority areas 1990-2016: a systematic analysis for the Global Burden of Disease Study 2016. Lancet. 2018 Nov; 392(10158):1647-61.

3 Jinks C, Jordan K, Ong BN, Croft P. A brief screening tool for knee pain in primary care (KNEST). 2. Results from a survey in the general population aged 50 and over. Rheumatology (Oxford). 2004 Jan;43(1):55-61.

4 Häuser W, Schmutzer G, Hinz A, Hilbert A, Brähler E. [Prevalence of chronic pain in Germany. A representative survey of the general population]. Schmerz. 2013 Feb;27(1):46-55.

5 Brantingham JW, Globe G, Pollard H, Hicks M, Korporaal C, Hoskins W. Manipulative therapy for lower extremity conditions: expansion of literature review. J Manipulative Physiol Ther. 2009 Jan;32(1):53-71.
6 Gross A, Miller J, D'Sylva J, Burnie SJ, Goldsmith CH, Graham N, et al. Manipulation or mobilisation for neck pain. Cochrane Database Syst Rev. 2010 Jan 20;(1):CD004249.

7 Vincent K, Maigne JY, Fischhoff C, Lanlo O, Dagenais S. Systematic review of manual therapies for nonspecific neck pain. Joint Bone Spine. 2013 Oct;80(5):508-15.

8 Diercks R, Bron C, Dorrestijn O, Meskers C, Naber R, de Ruiter T, et al.; Dutch Orthopaedic Association. Guideline for diagnosis and treatment of subacromial pain syndrome: a multidisciplinary review by the Dutch Orthopaedic Association. Acta Orthop. 2014 Jun;85(3):314-22.

9 National Institute for Health and Care Excellence (NICE). Osteoarthritis: care and management. Clinical guideline [CG177]London: National Collaborating Centre for Chronic Conditions at the Royal College of Physicians; 2014.

10 Brunner U, Liem D. S2e-Leitlinie „Rotatorenmanschette". Deutsche Gesellschaft für Orthopädie und Orthopädische Chirurgie. DGOOC; 2017.

11 Bundesärztekammer (BÄK). Kassenärztliche Bundesvereinigung (KBV), (AWMF) AdWMF. Nationale Versorgungsleitlinie Nichtspezifischer Kreuzschmerz - Langfassung. 2. Auflage, Version 1 ed. 2017.
12 Jobst D, Mücke M. Knieschmerz bei Arthrosezeichen. DEGAM S1- Handlungsempfehlung. AWMF online; 2017. p. 8.

13 Coulter ID, Crawford C, Hurwitz EL, Vernon H, Khorsan R, Suttorp Booth M, et al. Manipulation and mobilization for treating chronic low back pain: a systematic review and meta-analysis. Spine J. 2018 May;18(5):866-79.

14 Erlbeck A. [Error in drug prescription. Prescription for NSAR until the patient bleeds to death]. MMW Fortschr Med. 2003 Sep; 145(38):15.

15 Rabe K, Katsarava Z. [Medication-overuse headache]. MMW Fortschr Med. 2006 Aug;148(35-36):37-8.

16 Volkow ND, Collins FS. The Role of Science in Addressing the Opioid Crisis. N Engl J Med. 2017 Jul;377(4):391-4.

17 Foster NE, Anema JR, Cherkin D, Chou R, Cohen SP, Gross DP, et al.; Lancet Low Back Pain Series Working Group. Prevention and treatment of low back pain: evidence, challenges, and promising directions. Lancet. 2018 Jun;391(10137):2368-83.

18 Xue CC, Zhang AL, Lin V, Myers R, Polus B, Story DF. Acupuncture, chiropractic and osteopathy use in Australia: a national population survey. BMC Public Health. 2008 Apr; 8(1):105. 
19 Fawkes CA, Leach CM, Mathias S, Moore AP. A profile of osteopathic care in private practices in the United Kingdom: a national pilot using standardised data collection. Man Ther. 2014 Apr;19(2):125-30.

20 WHO. (World Health Organization). Benchmarks for training in osteopathy: benchmarks for training in traditional complementary and alternative medicine. Geneva: World Health Organization; 2010.

21 Franke H, Franke J-D, Fryer G. Osteopathic manipulative treatment for chronic nonspecific neck pain: A systematic review and metaanalysis. Int JOsteopath Med.2015;18(4):25567.

22 Franke H, Franke JD, Fryer G. Osteopathic manipulative treatment for nonspecific low back pain: a systematic review and meta-analysis. BMC Musculoskelet Disord. 2014 Aug;15(1):286.

23 Dal Farra F, Risio RG, Vismara L, Bergna A Effectiveness of osteopathic interventions in chronic non-specific low back pain: A systematic review and meta-analysis. Complement Ther Med. 2021 Jan;56:102616.

24 Knebl JA, Shores JH, Gamber RG, Gray WT, Herron KM. Improving functional ability in the elderly via the Spencer technique, an osteopathic manipulative treatment: a randomized, controlled trial. J Am Osteopath Assoc. 2002 Jul;102(7):387-96.

25 Schwerla F, Hinse T, Klosterkamp M, Schmitt T, Rütz M, Resch KL. Osteopathic treatment of patients with shoulder pain. A pragmatic randomized controlled trial. J Bodyw Mov Ther. 2020 Jul;24(3):21-8.

26 Bube J, Hettasch J. Osteopathic Treatment of Patients with Shoulder Pain. A Randomized Controlled Trial [Thesis]. German Academy of Osteopathy. Abstract only. Available through. http://www.osteopathic-research. com; 2009.

27 Weitendorff A. Effectiveness of osteopathic treatment in patients with chronic knee pain. A randomized con-trolled trial [Thesis]. German Academy of Osteopathy. Abstract only. Available through. http://www.osteopathicresearch.com; 2018

28 Huskisson EC. Measurement of pain. Lancet. 1974 Nov;2(7889):1127-31.

29 Salaffi F, Stancati A, Silvestri CA, Ciapetti A, Grassi W. Minimal clinically important changes in chronic musculoskeletal pain intensity measured on a numerical rating scale. Eur J Pain. 2004 Aug;8(4):283-91

30 Kovacs FM, Abraira V, Royuela A, Corcoll J, Alegre L, Cano A, et al. Minimal clinically important change for pain intensity and disability in patients with nonspecific low back pain. Spine. 2007 Dec;32(25):2915-20.

31 Lauche R, Langhorst J, Dobos GJ, Cramer H. Clinically meaningful differences in pain, disability and quality of life for chronic nonspecific neck pain - a reanalysis of 4 randomized controlled trials of cupping therapy. Complement Ther Med. 2013 Aug;21(4):342-7.

32 Bullinger $M$, Kirchberger I, Ware J. Der deutsche SF-36 Health Survey Übersetzung und psychometrische Testung eines krankheitsbergreifenden Instruments zur Erfassung der gesundheitsbezogenen Lebensqualität. Z Gesundhwiss. 1995;3(1):21-36.
33 Ware J, Jr., Kosinski M, Keller SD. A 12-Item Short-Form Health Survey: construction of scales and preliminary tests of reliability and validity. Med Care. 1996 Mar;34(3):220-33.

34 Bullinger M, Kirchberger I. SF-36 Fragebogen zum Gesundheitszustand. Göttingen: Hogrefe; 1998.

35 Resnick B, Nahm ES. Reliability and validity testing of the revised 12-item Short-Form Health Survey in older adults. J Nurs Meas. 2001 Fall;9(2):151-61.

36 Vernon H, Mior S. The Neck Disability Index: a study of reliability and validity. J Manipulative Physiol Ther. 1991 Sep;14(7):409-15.

37 Cramer H, Lauche R, Langhorst J, Dobos GJ, Michalsen A. Validation of the German version of the Neck Disability Index (NDI). BMC Musculoskelet Disord. 2014 Mar;15(1):91.

38 Manniche C, Asmussen K, Lauritsen B, Vinterberg H, Kreiner S, Jordan A. Low Back Pain Rating scale: validation of a tool for assessment of low back pain. Pain. 1994 Jun;57(3):317-26.

39 Nuhr MJ, Crevenna R, Quittan M, Auterith A, Wiesinger GF, Brockow T, et al. Cross-cultural adaption of the Manniche questionnaire for German-speaking low back pain patients. J Rehabil Med. 2004 Nov;36(6):267-72.

40 Copay AG, Glassman SD, Subach BR, Berven S, Schuler TC, Carreon LY. Minimum clinically important difference in lumbar spine surgery patients: a choice of methods using the Oswestry Disability Index, Medical Outcomes Study questionnaire Short Form 36, and pain scales. Spine J. 2008 NovDec;8(6):968-74.

41 Hudak PL, Amadio PC, Bombardier C, Beaton D, Cole D, Davis A, et al.; The Upper Extremity Collaborative Group (UECG). Development of an upper extremity outcome measure: the DASH (disabilities of the arm, shoulder and hand) [corrected]. Am J Ind Med. 1996 Jun;29(6):602-8.

42 Offenbächer M, Ewert T, Sangha O, Stucki G. Validation of a German version of the 'Disabilities of Arm, Shoulder and Hand' questionnaire (DASH-G). Z Rheumatol. 2003 Apr;62(2):168-77.

43 Malay S, Chung KC; SUN Study Group. The minimal clinically important difference after simple decompression for ulnar neuropathy at the elbow. J Hand Surg Am. 2013 Apr;38(4):652-9.

44 Bellamy N, Buchanan WW, Goldsmith $\mathrm{CH}$, Campbell J, Stitt LW. Validation study of WOMAC: a health status instrument for measuring clinically important patient relevant outcomes to antirheumatic drug therapy in patients with osteoarthritis of the hip or knee. J Rheumatol. 1988 Dec;15(12):1833-40.

45 Insall JN, Dorr LD, Scott RD, Scott WN. Rationale of the Knee Society clinical rating system. Clin Orthop Relat Res. 1989 Nov;\&NA;(248):13-4.

46 Stucki G, Meier D, Stucki S, Michel BA, Tyndall AG, Dick W, et al. [Evaluation of a German version of WOMAC (Western Ontario and McMaster Universities) Arthrosis Index]. Z Rheumatol. 1996 Jan-Feb;55(1):40-9.
47 Clement ND, Bardgett M, Weir D, Holland J, Gerrand C, Deehan DJ. What is the Minimum Clinically Important Difference for the WOMAC Index After TKA? Clin Orthop Relat Res. 2018 Oct;476(10):2005-14.

48 Lequesne MG. The algofunctional indices for hip and knee osteoarthritis. J Rheumatol. 1997 Apr;24(4):779-81.

49 Stucki G, Sangha O, Stucki S, Michel BA, Tyndall A, Dick W, et al. Comparison of the WOMAC (Western Ontario and McMaster Universities) osteoarthritis index and a selfreport format of the self-administered Lequesne-Algofunctional index in patients with knee and hip osteoarthritis. Osteoarthritis Cartilage. 1998 Mar;6(2):79-86.

50 Ludwig FJ, Melzer C, Grimmig H, Daalmann $\mathrm{HH}$. [Cross cultural adaptation of the lequesne algofunctional indices for german speaking patients with osteoarthritis of the hip and the knee]. Rehabilitation (Stuttg). 2002 Aug;41(4):249-57

51 Reginster JY, Dudler J, Blicharski T, Pavelka K. Pharmaceutical-grade Chondroitin sulfate is as effective as celecoxib and superior to placebo in symptomatic knee osteoarthritis: the ChONdroitin versus CElecoxib versus Placebo Trial (CONCEPT). Ann Rheum Dis. 2017 Sep;76(9):1537-43.

52 SAS Institute Inc. Copyright $($ 2002-2012 by SAS Institute Inc., Cary, NC, USA. SAS and all other SAS Institute Inc. product or service names are registered trademarks or trademarks of SAS Institute Inc., Cary, NC, USA.

53 R Core Team. R: A language and environment for statistical computing. In: $\mathrm{R}$ Foundation for Statistical Computing, editor. Vienna, Austria https://www.R-project.org/; 2020.

54 Degenhardt BF, Johnson JC, Gross SR, Hagan C, Lund G, Curry WJ. Preliminary findings on the use of osteopathic manipulative treatment: outcomes during the formation of the practicebased research network, DO-Touch.NET. J Am Osteopath Assoc. 2014 Mar;114(3):154-70.

55 Posadzki P, Ernst E. Osteopathy for musculoskeletal pain patients: a systematic review of randomized controlled trials. Clin Rheumatol. 2011 Feb;30(2):285-91.

56 Verhaeghe N, Schepers J, van Dun P, Annemans L. Osteopathic care for spinal complaints: A systematic literature review. PLoS One. 2018 Nov;13(11):e0206284.

57 Rotter G, Fernholz I, Binting S, Keller T, Roll S, Kass B, et al. The effect of osteopathic medicine on pain in musicians with nonspecific chronic neck pain: a randomized controlled trial. Ther Adv Musculoskelet Dis. 2020 Dec 10;12:1759720X20979853.

58 Martí-Salvador M, Hidalgo-Moreno L, Doménech-Fernández J, Lisón JF, Arguisuelas MD. Osteopathic Manipulative Treatment Including Specific Diaphragm Techniques Improves Pain and Disability in Chronic Nonspecific Low Back Pain: A Randomized Trial. Arch Phys Med Rehabil. 2018 Sep;99(9):1720-9.

59 Tamer S, Öz M, Ülger Ö. The effect of visceral osteopathic manual therapy applications on pain, quality of life and function in patients with chronic nonspecific low back pain. J Back Musculoskeletal Rehabil. 2017;30(3):419-25. 
60 Jorritsma W, Dijkstra PU, de Vries GE, Geertzen JH, Reneman MF. Detecting relevant changes and responsiveness of Neck Pain and Disability Scale and Neck Disability Index. Eur Spine J. 2012 Dec;21(12):25507.

61 Schellingerhout JM, Verhagen AP, Heymans MW, Koes BW, de Vet HC, Terwee CB. Measurement properties of disease-specific questionnaires in patients with neck pain: a systematic review. Qual Life Res. 2012 May;21(4):659-70.

62 Lauridsen $\mathrm{HH}$, Hartvigsen J, Manniche C, Korsholm L, Grunnet-Nilsson N. Responsiveness and minimal clinically important difference for pain and disability instruments in low back pain patients. BMC Musculoskelet Disord. 2006 Oct;7(1):82.

63 Negahban H, Behtash Z, Sohani SM, Salehi R. Responsiveness of two Persian-versions of shoulder outcome measures following physiotherapy intervention in patients with shoul- der disorders. Disabil Rehabil. 2015; 37(24):2300-4

64 Degenhardt BF, Johnson JC, Brooks WJ, Norman L. Characterizing Adverse Events Reported Immediately After Osteopathic Manipulative Treatment. J Am Osteopath Assoc. 2018 Mar;118(3):141-9.

65 World Medical Association. Declaration of Helsinki - Ethical Principles for Medical Research Involving Human Subjects. amended by the 59th WMA General Assembly, Seoul, Korea, October 2008.

66 McCarney R, Warner J, Iliffe S, van Haselen R, Griffin M, Fisher P. The Hawthorne Effect: a randomised, controlled trial. BMC Med Res Methodol. 2007 Jul;7(1):30-30.

67 Monahan T, Fisher JA. Benefits of "Observer Effects": lessons from the Field. Qual Res. 2010 Jun;10(3):357-76.

68 Ruffini N, D’Alessandro G, Mariani N, Pollastrelli A, Cardinali L, Cerritelli F. Variations of high frequency parameter of heart rate variability following osteopathic manipulative treatment in healthy subjects compared to control group and sham therapy: randomized controlled trial. Front Neurosci. 2015 Aug;9:272.

69 Jacq O, Arnulf I, Similowski T, Attali V. Upper airway stabilization by osteopathic manipulation of the sphenopalatine ganglion versus sham manipulation in OSAS patients: a proof-of-concept, randomized, crossover, double-blind, controlled study. BMC Complement Altern Med. 2017 Dec;17(1):546

70 Cerritelli F, Verzella M, Cicchitti L, D'Alessandro G, Vanacore N. The paradox of sham therapy and placebo effect in osteopathy: A systematic review. Medicine (Baltimore). 2016 Aug;95(35):e4728.

71 Moustgaard H, Clayton GL, Jones HE, Boutron I, Jørgensen L, Laursen DR, et al. Impact of blinding on estimated treatment effects in randomised clinical trials: meta-epidemiological study. BMJ. 2020 Jan;368:16802. 